\title{
Peran Public Relations dalam Manajemen Event (Studi Terhadap Peran Public Relations Galeria Mall dan Plaza Ambarrukmo dalam Pengelolaan Event Tahun 2013)
}

\author{
Mutia Dewi \\ Dosen Program Studi Ilmu Komunikasi \\ Universitas Islam Indonesia (UII), Yogyakarta \\ Marcha Runyke \\ Alumnus Program Studi Ilmu Komunikasi \\ Universitas Islam Indonesia (UII), Yogyakarta
}

\begin{abstract}
Nowadays, Indonesian business are growing and developing rapidly. Every year, department store or mall are being build in many cities in Indonesian. This condition make every mall have to think about how to deal with the competition. Event are one program did by the mall's management in order to attract customer. Event has to be well managed so that the event can give advantage for the mall. Event management is one of Public Relations (PR) departement's duty.

This research discuss about Public Relations role in Galleria Mall PR Department and Plaza Ambarrukmo PR Department, related to event management. Both PR department do the writing media release, publicity, and media relations. Meanwhile there are difference role between Galeria Mall PR Department and Plaza Ambarrukmo PR Department in the role as conceptor, stage manager, and supporting unit.
\end{abstract}

Keywords: Public Relations, Event Management, Public Relations role

\begin{abstract}
Abstrak
Dunia bisnis di Indonesia sedang mengalami pertumbuhan dan perkembangan yang pesat. Setiap tahunnya pasti selalu ada pusat perbelanjaan yang baru dibangun terutama di kota-kota besar. Event merupakan salah satu usaha yang dilakukan oleh pusat perbelanjaan untuk mendekatkan diri dengan pengunjung atau customer. Agar event tersebut dapat memberikan hasil positif bagi pusat perbelanjaan, maka perlu dikelola dengan baik. Pengelolaan event merupakan tugas dari departemen Public Relations.

Penelitian ini membahas tentang peran Public Relations di dua pusat perbelanjaan di Yogyakarta yakni Galeria Mall dan Plaza Ambarrukmo berkaitan dengan pengelolaan event. Dari hasil penelitian diperoleh bahwa PR di kedua mall tersebut memiliki kesamaan peran dalam hal menulis rilis untuk media, publisitas, dan hubungan dengan media. Sementara perbedaan PR di kedua mall tersebut adalah dalam hal peran sebagai konseptor, stage manager, dan support.
\end{abstract}

Kata Kunci: Public Relations, Manajemen Event, Peran Public Relations 


\section{Pendahuluan}

Dunia bisnis di Indonesia sedang mengalami pertumbuhan dan perkembangan yang pesat. Setiap tahunnya pasti selalu ada pusat perbelanjaan yang baru dibangun terutama di kota-kota besar. Pusat perbelanjaan atau yang lebih sering disebut dengan mall kini bermunculan dan berimplikasi pada persaingan antara mall-mall yang sudah ada dengan mallmall yang baru. Sebelumnya di Yogyakarta hanya ada Malioboro Mall dan Galeria Mall, lalu bertambah dengan dua mall lainnya yaitu Plaza Ambarrukmo dan Saphir Square.

Mall-mall di Yogyakarta dihadapkan pada tantangan bagaimana manajemen dapat menjalankan bisnis dengan baik serta menghadirkan sesuatu yang berkualitas sehingga dapat menarik pengunjung sekaligus customer. Mulai dari strategi komunikasi pemasaran, fasilitas yang disediakan, jumlah serta variasi tenant, customer relations hingga event-event yang diselenggarakan.

Melihat dari banyaknya strategi yang dilakukan diatas, ketertarikan tiap pengunjung terhadap sebuah mall pasti dilatar-belakangi dengan alasan yang berbeda-beda. Ada pengunjung yang tertarik pada tenant-tenant yang berada di dalam mall tersebut, kemudian terselenggaranya event yang menampilkan talent-talent serta berbagai macam hiburan dan yang paling menarik adalah dengan adanya program-program yang ditawarkan seperti diskon, extra time, dan late night sale, ini merupakan hasil kerjasama antara manajemen office mall dengan para tenant-nya.

Masyarakat dengan bebas bisa memilih mall mana yang sesuai dengan keinginan dan kebutuhannya. Kita dapat melihat fenomena mengenai gaya hidup yang terus berubah dari masa ke masa mengikuti perkembangan zaman, hal tersebut dapat berpengaruh pada keinginan dan kebutuhan masyarakat modern saat ini. Kebiasaan masyarakat yang mengarah pada konsumerisme membuat mereka membutuhkan tempat yang dapat memenuhi berbagai macam kebutuhannya.

Berangkat dari fenomena inilah banyak developer yang berlomba-lomba membangun mall sebagai tempat yang dapat menjadi alternatif pilihan rekreasi bagi masyarakat. Pada awalnya, mall dibangun sebagai sarana untuk berbelanja, namun belakangan ini bukan saja menjadi sarana berbelanja tetapi juga sebagai tempat sarana berlibur bagi masyarakat. Dengan begitu, orang-orang merasa bahwa segala aktivitasnya dapat dilakukan di dalam mall tanpa perlu berpindah tempat lagi. Tak heran apabila pembangunan mall merupakan salah satu investasi bisnis yang menjanjikan untuk masa depan.

Menariknya, ketika mall yang ada di Yogyakarta saat ini hanya tiga, antara lain Galeria Mall, Plaza Ambarrukmo dan Malioboro Mall, tentunya tingkat 
Mutia Dewi \& Marcha Runyke, Peran Public Relations dalam Manajemen Event (Studi Terhadap Peran Public Relations Galeria Mall dan Plaza Ambarrukmo dalam Pengelolaan Event Tahun 2013)

kompetisi yang terjadi sangat tinggi. Setiap mall berusaha dan menampilkan sesuatu yang menarik agar tetap mampu bertahan, oleh karena itu suatu perusahaan yang bergerak dalam bidang bisnis harus mempunyai sesuatu yang dapat diandalkan untuk menghadapi persaingan. Mulai dari perbaikan fasilitas setiap tahunnya, perubahan variasi tenant, sampai dengan strategi komunikasi pemasaran. Dan di sini, event merupakan salah satu program Public Relations yang dapat dijadikan sebagai langkah untuk mendekatkan diri dengan pengunjung atau customer.

Menurut William O' Toole dan Phyllis Mikolaitis (2007), suatu event perusahaan mungkin memiliki banyak tujuan. Event perusahaan merupakan bagian dari strategi komunikasi perusahaan. Event bersentuhan langsung dengan pengunjung atau customer, sehingga event menjadi jembatan komunikasi antara mall dengan pengunjung atau customer. Pengelolaan event apabila dilakukan dengan baik kemudian menghasilkan event yang berkualitas, maka event merupakan salah satu senjata dalam persaingan menarik perhatian pengunjung atau customer sebanyak-banyaknya.

Banyak atau sedikitnya pengunjung yang datang dapat dilihat dari data volume pengunjung. Tentunya, Divisi Public Relations atau Humas-lah yang berperan dalam pembuatan data tersebut. Divisi Public Relations erat kaitannya dengan segala bentuk aktivitas mengenai perusahaan, antara lain menjalin hubungan baik dengan media (media relations), membuat press release, cutomer relations, merencanakan serta mengorganisasikan event, dan masih banyak lagi. Tak heran apabila Public Relations memiliki peranan yang penting dalam proses pengelolaan sebuah event.

Ketika event dihadirkan dan mendapat perhatian serta apresiasi dari pengunjung, maka untuk selanjutnya pihak manajemen mall akan membuat event dengan perencanaan yang lebih baik lagi. Dalam pengelolaan event, hal yang paling banyak ditemukan adalah tema event yang berbeda-beda, mulai dari talent yang hadir, lokasi tempat event diadakan, program-program yang menarik minat pengunjung dan lain-lain. Hal ini tentunya melalui beberapa tahap yaitu perencanaan, pengorganisasian, pengarahan dan pengimplementasian serta pengendalian dan pengawasan.

Hampir di setiap perusahaan mempunyai Divisi Public Relations (PR) atau Humas. PR berada di dalam fungsi manajemen sebuah perusahaan untuk melakukan kegiatan komunikasi yang efektif, membentuk citra positif perusahaan, membangun kredibilitas yang terpercaya dan pencegahan terhadap kemungkinan adanya resiko atau isu. Menjadi seorang PR harus benar-benar memahami dan mengetahui product knowledge mengenai perusahaan tempat dia bekerja. 
Semua lembaga atau perusahaan mempunyai strategi yang berbeda-beda dalam menjalankan tujuan perusahaannya. Ada kalanya suatu perusahaan menggunakan cara yang berbeda-beda di setiap program dengan maksud ingin mencapai tujuan yang telah direncanakan. Tentu saja sebagai Public Relations yang berfungsi menciptakan jati diri perusahaan harus mempunyai taktik agar program tersebut berjalan dengan lancar.

Dengan mengetahui segala sesuatu yang berkaitan dengan perusahaan, Public Relations menjadi sumber informasi bagi pihak-pihak terkait seperti pihak internal (pimpinan perusahaan dan karyawan) dan pihak eksternal (publik atau masyarakat dan media). Oleh karena itu, PR dituntut untuk dapat berkomunikasi dengan baik dan mampu menganalisis opini publik untuk mendapatkan good will dan good image.

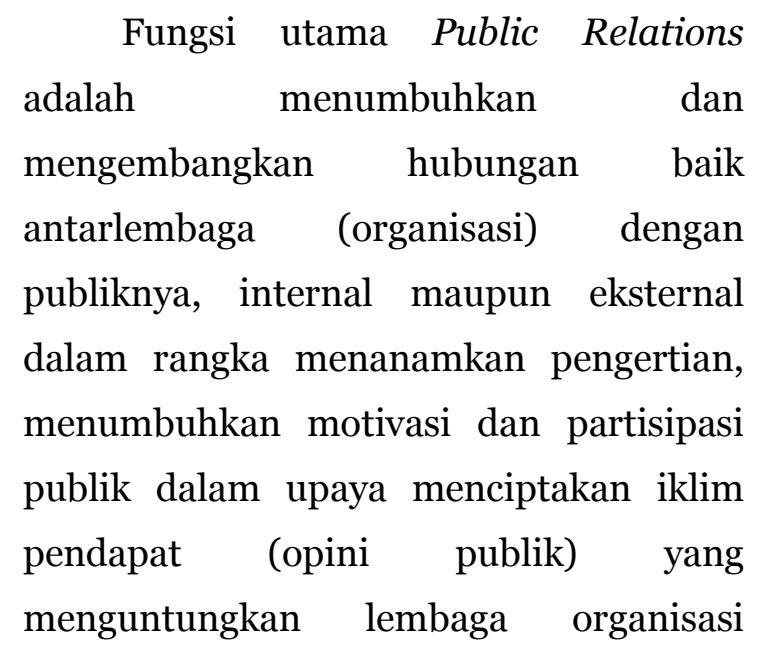
(Nova, 2009: 38).

Dilihat dari fungsi Public Relations diatas, tentunya peran Public Relations sangat penting diterapkan dalam sebuah perusahaan. Hal ini juga terjadi di pusatpusat perbelanjaan, dilihat dari perkembangannya pusat-pusat perbelanjaan di Indonesia mengalami perkembangan yang sangat signifikan, hal ini dikarenakan meningkatnya daya beli masyarakat Indonesia yang konsumtif serta gaya hidup yang semakin modern sehingga pusat-pusat perbelanjaan pun terus tumbuh diiringi kebutuhan masyarakat yang semakin kompleks.

\section{Peran Public Relations}

Dalam suatu organisasi dapat dibagi dalam empat kategori berikut (Nova, 2009: 45):

1) Penasehat ahli (expert prescriber)

Seorang praktisi pakar Public Relations yang berpengalaman dan memiliki kemampuan tinggi dapat membantu mencari solusi dalam menyelesaikan masalah yang berhubungan dengan publiknya (Public Relationship).

2) Fasilitator komunikasi (communication facilitator)

Dalam hal ini, praktisi Public Relations bertindak sebagai komunikator atau mediator yang membantu pihak manajemen mendengar apa yang diinginkan dan diharapkan oleh publiknya. Di pihak lain, praktisi Public Relations juga dituntut menjelaskan kembali keinginan, kebijakan dan harapan 
Mutia Dewi \& Marcha Runyke, Peran Public Relations dalam Manajemen Event (Studi Terhadap Peran Public Relations Galeria Mall dan Plaza Ambarrukmo dalam Pengelolaan Event Tahun 2013)

organisasi kepada publiknya. Dengan komunikasi timbal balik diharapkan dapat tercipta saling pengertian, saling percaya, saling menghargai, saling mendukung dan toleransi yang baik dari kedua belah pihak.

3) Fasilitator proses pemecahan masalah (problem solving process fasilitator)

Peranan praktisi Public Relations dalam proses pemecahan persoalan Public Relations ini merupakan bagian dari tim manajemen. Hal ini dimaksudkan untuk membantu pimpinan organisasi baik sebagai penasihat (adviser) hingga mengambil tindakan eksekusi (keputusan) dalam mengatasi persoalan atau krisis yang tengah dihadapi secara rasional dan professional. Dalam menghadapi suatu krisis yang terjadi maka akan dibentuk suatu tim posko yang dikoordinasi praktisi Public Relations dengan melibatkan berbagai departemen dan keahlian dalam satu tim khusus untuk membantu organisasi, perusahaan dan produk yang tengah didera krisis tertentu.

4) Teknisi komunikasi (communication technician)

Teknisi komunikasi berbeda dengan tiga peranan praktisi Public Relations profesional yang terkait erat dengan fungsi dan peranan manajemen organisasi. Peranan communication technician ini menjadikan praktisi
Public Relations sebagai journalist in resident yang hanya menyediakan layanan teknis komunikasi atau dikenal dengan method of communication.

\section{Manajemen Event}

Perusahaan yang bergerak dalam penyelenggaraan event memberikan pelayanannya dalam hampir seluruh aspek, seperti mendesain tempat penyelenggaraan event, menyusun tata letak untuk fasilitas yang diperlukan event, mempersiapkan tata cahaya, tata suara, penggunaan teknologi pada penyelenggaraan event (tele conference, video, dvd, projection) serta efek spesial lainnya yang diperlukan dalam event yang tentunya disesuaikan dengan kebutuhan event itu sendiri. Tentunya kebutuhan setiap event tidak sama antara satu dengan lainnya. Sehingga sangat dibutuhkan kreativitas yang tinggi. Hal ini berhubungan dengan pengalaman yang akan didapatkan oleh peserta, pengunjung atau pengguna event lainnya. Pengalaman yang diberikan haruslah pengalaman yang tidak terlupakan, karena salah satu kunci sukses event adalah dapat memberikan pengalaman luar biasa bagi peserta (Noor, 2009: 74).

\section{Metode Penelitian}

Paradigma penelitian ini adalah paradigma konstruktivisme dan menggunakan pendekatan kualitatif 
deskriptif. Lokasi penelitian berada di dua lokasi yaitu Galeria Mall dan Plaza Ambarrukmo. Galeria Mall beralamat di Jl Sudirman 99-101 Yogyakarta sedangkan Plaza Ambarrukmo beralamat di $\mathrm{Jl}$. Laksda Adisucipto $\mathrm{km} \mathrm{6,} \mathrm{Yogyakarta.}$ Narasumber disini adalah PR dan Divisi Event terkait dari setiap mall sebagai pihak yang melakukan perannya sebagai PR dalam pengelolaan event.

\section{Hasil dan Pembahasan}

Telah banyak event- event yang rutin diselenggarakan tiap bulannya oleh Galeria Mall. Event regular yang rutin diadakan oleh Galleria Mall adalah The Stage On Gale dan Gale Ceria. Galeria Mall sebagai pusat perbelanjaan yang sudah lama berdiri di Yogyakarta perlu sesuatu untuk mempertahankan eksistensinya sebagai mall yang konsisten mempertahankan sentuhan suasana keramahan Jogja yang hangat dan bersahabat. Dilihat dari perkembangannya, Galeria Mall ingin memenuhi kebutuhan masyarakat Jogja dengan menghadirkan kebaruankebaruan yang sesuai tuntutan gaya hidup masa kini.

Salah satu bagian dari strategi Galeria Mall tercermin pada event promosi dan pameran yang rutin dilaksanakannya. Kemudian, hubungan baik serta kerjasama dengan seluruh tenant, Event Orgnizer, sponsor maupun pihak-pihak terkait harus selalu dibina agar tercipta hubungan yang harmonis. Dengan semua kerja keras yang telah dilakukan selama ini, Galeria Mall tetap dapat mempertahankan eksistensinya sebagai pusat perbelanjaan yang tak pernah sepi pengunjung dan mampu bersaing dalam menghadapi para kompetitor.

Sedangkan Plaza Ambarrukmo, yang merupakan mall terbesar di Yogyakarta yang memiliki banyak aktivitas untuk menarik perhatian pengunjung, mulai dari strategi marketing communication, publisitas, media relations dan juga event-event yang diadakan. Salah satu keunggulan yang dimiliki Plaza Ambarrukmo adalah dengan banyaknya tenant yang dimiliki, mall ini dapat menyelenggarakan berbagai event yang menarik dan menghibur karena adanya kerjasama yang terjalin dengan baik antara kedua belah pihak yaitu manajemen office dan para tenant.

\section{1) Jenis-Jenis Event}

Galeria Mall memililki tiga event regular yaitu Gale Ceria, The Stage on Gale dan Extra Time. Karena di setiap bulannya Galeria mengadakan event yang berbeda, maka biasanya event disesuaikan dengan moment yang saat itu tengah berlangsung. Selain ketiga event diatas, ada juga kalender event nasional antara lain ramadhan, natal dan kemerdekaan. Sedangkan event seperti Valentine, Hari Ibu, Halloween 
Mutia Dewi \& Marcha Runyke, Peran Public Relations dalam Manajemen Event (Studi Terhadap Peran Public Relations Galeria Mall dan Plaza Ambarrukmo dalam Pengelolaan Event Tahun 2013)

dan sebagainya masuk di event regular yang mengambil moment special.

Plaza Ambarrukmo memiliki dua jenis event, yaitu event in house dan event perbayar dari luar. Event in house memang sudah ada perencanaannya dalam setahun seperti event besar antara lain imlek, ulang tahun Plaza Ambarrukmo yang jatuh pada bulan Maret, kemudian lebaran dan natal. Jadi dalam setahun Plaza Ambarrukmo mengadakan empat kali event besar tersebut. Sedangkan event perbayar dari luar yang sifatnya sewa akan berkoordinasi dengan pihak leasing.

\section{2) Manajemen Event}

Proses perencanaan event dimulai menentukan tujuan yang dapat diterima dengan jelas oleh setiap anggota tim yang akan terlibat dalam pelaksanaan event. Tujuan merupakan langkah awal dalam setiap perencanaan sebuah

event. Tujuan diselenggarakannya suatu event dapat berupa: pembelajaran, bertukar pikiran, sosialisasi, peringatan, hiburan, mempromosikan produk baru perusahaan atau meningkatkan pendapatan perusahaan dan sebagainya (Noor, 2009: 104).

Perencana event internal atau eksternal dapat menghasilkan proyek event tambahan dengan mengusulkan kepada manajemen untuk menyelenggarakan event yang member dampak dan menarik perhatian pada perilaku atau nilai tertentu. Suatu event yang diselenggarakan secara harmonis dapat memperkuat perilaku yang diinginkan perusahaan dari para pekerjanya (O' Toole, William dan Phyllis Mikolaitis, 2007: 9).

\section{a. Perencanaan}

Proses perencanaan yang dilakukan untuk menetapkan tujuan Galeria Mall dalam membuat event diwujudkan dalam bentuk meeting untuk membahas mengenai apa saja langkah-langkah dan serangkaian kegiatan untuk mencapai hasil yang diinginkan dengan membuat rundown acara.

Tahap perencanaan event-event besar Plaza Ambarrukmo pada dasarnya sudah ada plan-nya, jadi panitia hanya tinggal mencari jadwal yang kosong kemudian dikoordinasikan dengan pihak leasing. Setelah berkoordinasi dengan pihak leasing, panitia akan menyampaikan hal tersebut kepada Chief Marketing Communication. Dari Chief Marketing Communication akan disampaikan General Manager kemudian diteruskan kepada Direksi. Apabila dari Direksi ada revisi, maka panitia akan merevisi ulang, dan apabila Direksi telah menyetujui, event baru bisa dilaksanakan. 


\section{b. Pengorganisasian}

Staf humas harus bekerjasama secara erat dengan bagian-bagian lain pada organisasi atau perusahaan. Bagian humas harus bekerjasama dengan bagian pemasaran atau keuangan. Bagian humas juga harus bekerjasama dengan bagian personalia, bagian legal (hukum), teknik dan sebagainya (Morissan, 2008: 99).

Proses pengorganisasian dalam event Galeria Mall adalah memastikan bagaimana hasil dari perencanaan dapat dijalankan dengan baik. Untuk itu, pemberian tugas diberikan kepada masing-masing panitia sesuai skill yang dimiliki, job desk ini nantinya akan berlaku selama event berlangsung. Setelah itu, barulah pengalokasian sumber daya secara tepat serta pengaturan kegiatan yang terkoordinir dengan baik. Tentunya dalam proses pengorganisasian ini kerjasama sangat dibutuhkan demi kelancaran dan kesuksesan event.

Didalam

Communication (Marcom) Plaza

Ambarrukmo hanya ada delapan orang sedangkan event yang diadakan besar dan membutuhkan perhatian yang detail di setiap tahap, oleh karena itu perlu adanya kerjasama yang baik antar karyawan, terlebih pemantauan yang dilakukan oleh Chief Marcom Plaza Ambarrukmo. c. Pengarahan

dan

\section{Pengimplementasian}

Proses pengarahan langsung dari General Manager atau Promotion Manager maupun Chief Marcom kepada seluruh anggota panitia diberikan sebagai upaya untuk memotivasi dan menumbuhkan semangat agar dapat bekerja dengan giat serta membimbing dalam proses pelakasanaan rencana. Sedangkan implementasi program agar dapat dijalankan oleh seluruh panitia maka setiap panitia harus memiliki kesadaran dan tanggung jawab akan tugas yang sudah diberikan sesuai dengan kemampuan masing-masing.

\section{d. Pengendalian dan Pengawasan}

Proses pengawasan dan pengendalian ini dilakukan untuk memastikan seluruh rangkaian event yang telah direncanakan, diorganisasikan dan diimplementasikan telah berjalan sesuai target yang diharapkan. Disini Galeria Mall melakukan evaluasi kegiatan apakah terdapat kekurangan dalam pelaksanaan event dalam bentuk tindakan korektif. Dan apabila menemukan kekurangan, panita segera membahas dan mengambil alternatif solusi agar event selanjutnya tidak terjadi lagi.

Manajemen pengelolaan event Plaza Ambarrukmo yang terakhir juga melalui tahap evaluasi. Evaluasi 
Mutia Dewi \& Marcha Runyke, Peran Public Relations dalam Manajemen Event (Studi Terhadap Peran Public Relations Galeria Mall dan Plaza Ambarrukmo dalam Pengelolaan Event Tahun 2013)

biasanya disampaikan dari atasan melalui meeting. Dalam meeting tersebut akan dibahas mengenai segala sesuatu yang berkaitan dengan event termasuk tentang kelebihan dan kekurangan pada saat event berlangsung.

\section{3) Peran Public Relations dalam Pengelolaan Event}

Data yang diperoleh dari hasil penelitian kemudian dikelompokkan dalam indikator mengenai peran PR yakni menulis rilis untuk media, konseptor event, stage manager, supporting unit, publisitas, dan media relations.

Ada pun perbedaan peran PR antara Galeria Mall dan Ambarrukmo Plaza terletak pada kategori konseptor, stage manager, dan support. Dalam melakukan peran sebagai konseptor, PR Galeria Mall bekerjasama dengan Divisi Promosi untuk merancang acara. Sementara PR Ambarrukmo Plaza tidak berperan sebagai konseptor karena peran tersebut sudah menjadi tanggungjawab dari divisi Event.

PR Galeria Mall juga berperan sebagai stage manager yang bertugas mengatur jalannya event agar sesuai dengan perencanaan yang dibuat. Sementara PR Ambarrukmo Plaza tidak melakukan tugas ini karena telah menjadi tanggungjawab divisi lain yakni Divisi Event.

Peran PR Ambarrukmo Plaza dalam kaitannya dengan penyelenggaraan event lebih bersifat support. Pasalnya peran PR Plaza Ambarrukmo akan berbeda-beda di setiap event.

Tabel 1 Perbandingan Peran Public Relations dalam Pengelolaan Event

\begin{tabular}{|c|c|c|}
\hline Indikator & Galeria Mall & Plaza Ambarrukmo \\
\hline $\begin{array}{l}\text { Writing Media } \\
\text { Release }\end{array}$ & $\begin{array}{l}\text { Berperan aktif dalam pembuatan } \\
\text { release di setiap event yang akan } \\
\text { diselenggarakan dan mengirim release } \\
\text { tersebut kepada wartawan. }\end{array}$ & $\begin{array}{l}\text { Merupakan job description pada saat event } \\
\text { yang membuat media plan, press release, } \\
\text { naskah at lips, naskah iklan spot, talkshow dan } \\
\text { seluruh lampiran untuk materi promo event. }\end{array}$ \\
\hline Konseptor & $\begin{array}{l}\text { PR Galeria Mall pada saat perencanaan } \\
\text { berperan sebagai konseptor dibantu } \\
\text { dengan Staf Divisi Promosi lainnya. } \\
\text { Mulai daripemilihan tema, konsep, } \\
\text { koordinasi dengan pihak-pihak terkait, } \\
\text { pemilihan pengisi acara sampai } \\
\text { menghubungi para pengisi acara } \\
\text { dilakukan semua oleh Public Relations. }\end{array}$ & \\
\hline Stage Manager & $\begin{array}{l}\text { Pada saat pelaksanaan event peran PR } \\
\text { menjadi stage manager, dimana peran } \\
\text { ini bertugas mengatur jalannya event } \\
\text { agar sesuai dengan rundown yang } \\
\text { telah dibuat. Kemudian juga } \\
\text { mengontrol apakah MC dan pengisi } \\
\text { acara sudah sesuai dengan tema acara } \\
\text { serta memastikan kepada semua } \\
\text { pengisi acara sudah datang di lokasi. }\end{array}$ & $\begin{array}{l}\text { PR Plaza Ambarrukmo tidak berperan sebagai } \\
\text { konseptor maupun stage manager sebab } \\
\text { peran-peran tersebut merupakan peran yang } \\
\text { dipegang oleh Divisi Event sendiri. Sehingga } \\
\text { peran PR disini lebih kepada support apabila } \\
\text { dibutuhkan. }\end{array}$ \\
\hline
\end{tabular}




\begin{tabular}{|c|l|l|}
\hline Support & $\begin{array}{l}\text { PR Galeria Mall tidak berperan sebagai } \\
\text { support event, sebab mulai dari tahap } \\
\text { perencanaan PR Galeria Mall memiliki } \\
\text { peran yang lebih dari support event } \\
\text { yaitu konseptor dan stage manager. }\end{array}$ & $\begin{array}{l}\text { Peran PR Plaza Ambarrukmo bersifat support } \\
\text { apabila dibutuhkan. Sebab peran PR Plaza } \\
\text { Ambarrukmo akan berbeda-beda di setiap } \\
\text { event. Meskipun peran utama lebih kepada } \\
\text { publisitas, namun PR juga akan membantu } \\
\text { apapun jika dibutuhkan. }\end{array}$ \\
\hline Publisitas & $\begin{array}{l}\text { Dengan memberikan release kepada } \\
\text { wartawan dan meng-upload beberapa } \\
\text { informasi dan foto melalui facebook } \\
\text { dan twitter kemudian juga membuat } \\
\text { Surat pemberitahuan. }\end{array}$ & $\begin{array}{l}\text { Merupakan peran utama PR Plaza Ambarrukmo } \\
\text { pada saat pengelolaan event. Segala bentuk } \\
\text { publisitas dilakukan semuanya mulai dari media } \\
\text { internal dan media eksternal. }\end{array}$ \\
\hline Media Relations \\
$\begin{array}{l}\text { Berperan sebagai seseorang yang } \\
\text { bertugas menghubungi media untuk } \\
\text { memberitahukan mengenai event yang } \\
\text { diadakan dan mengundang wartawan } \\
\text { untuk datang dan meliput kegiatan di } \\
\text { lokasi event. Bahkan PR juga melayani } \\
\text { wawancara dengan wartawan saat } \\
\text { event sedang berjalan. }\end{array}$ & $\begin{array}{l}\text { Salah satu bentuk usaha yang dilakukan untuk } \\
\text { menjaga hubungan baik dengan pihak media } \\
\text { selalu berkomunikasi melalui wartawan dari } \\
\text { dan } \\
\text { tiap media serta memberi tahu tentang adanya } \\
\text { event di Plaza Ambarrukmo. }\end{array}$ \\
\hline
\end{tabular}

Dengan demikian, media relations

bisa diartikan, merupakan bagian dari Public Relations eksternal yang membina dan mengembangkan hubungan baik dengan media massa sebagai sarana komunikasi antara organisasi dan publiknya untuk mencapai tujuan organisasi (Iriantara, 2005: 32).

\section{4) Analisis SWOT}

Analisis SWOT digunakan sebagai salah satu cara untuk mengetahui kekuatan, kelemahan, peluang dan ancaman dalam melaksanan sebuah tujuan. Tujuan diadakannya event oleh Galeria Mall dan Plaza Ambarrukmo adalah meningkatkan citra di mata masyarakat, menarik pengunjung serta meningkatkan omset penjualan para

tenant.

\section{Tabel 2 Analisis SWOT Galeria Mall dalam Pengelolaan Event}

\begin{tabular}{|c|c|}
\hline Strength & $\begin{array}{l}\text { 1. Merupakan mall yang sudah lama berdiri dan memiliki brand } \\
\text { tersendiri. } \\
\text { 2. Adanya Divisi Promosi yang bekerjasama dengan pihak-pihak } \\
\text { terkait dalam menjalankan tugas. } \\
\text { 3. Memiliki agenda event yang rutin selalu digelar setiap bulannya. } \\
\text { 4. Customer relations yang baik sehingga bisa terjalin kerjasama } \\
\text { pada saat event berlangsung. } \\
\text { 5. Adanya media relations yang dapat memudahkan Public } \\
\text { Relations untuk mempublikasikan event. } \\
\text { 6. Adanya tambahan jam operasional pada saat event Extra Time. } \\
\text { 7. Memberikan pelayanan berupa parkir gratis pada penambahan } \\
\text { jam operasional saat event Extra Time. }\end{array}$ \\
\hline Weakness & $\begin{array}{l}\text { 1. Rutinnya mengadakan event hampir di setiap bulan menuntut } \\
\text { Galeria Mall untuk menciptakan ide-ide yang inovatif agar event } \\
\text { tidak terkesan monoton. } \\
\text { 2. Talent atau pengisi acara dalam mengaplikasikan tema yang } \\
\text { kurang dari segi performance. }\end{array}$ \\
\hline
\end{tabular}


Mutia Dewi \& Marcha Runyke, Peran Public Relations dalam Manajemen Event (Studi Terhadap Peran Public Relations Galeria Mall dan Plaza Ambarrukmo dalam Pengelolaan Event Tahun 2013)

\begin{tabular}{|l|l|}
\hline & $\begin{array}{l}\text { 3. Adanya beberapa talent yang kurang memperhatikan } \\
\text { kedisiplinan waktu. }\end{array}$ \\
\hline Opportunity & 1. $\begin{array}{l}\text { Rutinnya menggelar berbagai event dapat dijadikan sebuah } \\
\text { kesempatan untuk bersaing dengan mall lain. }\end{array}$ \\
& $\begin{array}{l}\text { 2. Dapat dijadikan kesempatan untuk menarik stakeholder. } \\
\text { 3. Building image yang berdampak jangka panjang. } \\
\text { 4. Meningkatkan traffic pengunjung. }\end{array}$ \\
& $\begin{array}{l}\text { 5. Menjadi jembatan komunikasi dengan pengunjung. } \\
\text { 6. Meningkatkan prospek bisnis tenant. }\end{array}$ \\
\hline Threat & 1. Rencana beberapa tahun kedepan bahwa akan dibangun beberapa \\
& mall baru di Yogyakarta. \\
& 2. Persaingan bisnis baru melalui event. \\
\hline
\end{tabular}

Penulis melihat bahwa peluang yang bisa diperoleh Galeria Mall dari rutinnya menggelar berbagai event dapat dijadikan sebuah kesempatan untuk bersaing dengan mall lain. Rutinnya mengadakan event hampir di setiap bulan menuntut Galeria Mall untuk menciptakan ide-ide yang inovatif agar event tidak terkesan monoton dan dapat terus meningkatkan kualitas event yang akan diadakan selanjutnya. Sedangkan hambatan yang ditemui dalam event adalah talent atau pengisi acara dalam mengaplikasikan tema yang selama ini kurang dari segi performance.

Tabel 3 Analisis SWOT Plaza Ambarrukmo dalam Pengelolaan Event

\begin{tabular}{|l|l|}
\hline Strength & $\begin{array}{l}\text { 1. } \begin{array}{l}\text { Plaza Ambarrukmo sebagai mall terbesar di Yogyakarta dan Jawa } \\
\text { Tengah. }\end{array} \\
\text { 2. Adanya planning mengenai event-event besar. } \\
\text { 3. Adanya Divisi Event yang khusus menangani event dan support } \\
\text { dari Public Relations. }\end{array}$ \\
& $\begin{array}{l}\text { 4. Terjalinnya media relations yang baik sebagai bentuk upaya } \\
\text { publisitas. }\end{array}$ \\
& $\begin{array}{l}\text { Kerjasama yang terjalin antara manajemen dengan } \\
\text { pihak tenant. }\end{array}$ \\
\hline Weakness & $\begin{array}{l}\text { 1. Penyelenggaraan event yang dilakukan pada saat yang hampir } \\
\text { bersamaan. }\end{array}$ \\
\hline Opportunity & $\begin{array}{l}\text { 1. Event yang besar sesuai dengan moment dapat meningkatkan } \\
\text { traffic pengunjung. }\end{array}$ \\
& $\begin{array}{l}\text { 2. Building image yang berdampak jangka panjang. } \\
\text { 3enjadi jembatan komunikasi dengan pengunjung. } \\
\text { 4. Meningkatkan omset penjualan para tenant. }\end{array}$ \\
\hline Threat & $\begin{array}{l}\text { 1. Akan banyak kompetitor (mall) di Yogyakarta. } \\
\text { 2. Penyelenggaraan event yang tidak dilakukan di mall. } \\
\text { 3. Kemacetan terjadi di sekitar Plaza Ambarrukmo saat event yang } \\
\text { diadakan saat weekend. }\end{array}$ \\
4. Konsep event tidak inovatif.
\end{tabular}




\section{Penutup}

Peran Public Relations dalam pengelolaan event di Galeria Mall sebagai konseptor, stage manager, fasilitator komunikasi (writing media release), fasilitator proses pemecahan masalah (problem solving process fasilitator) dan teknisi komunikasi (publisitas dan media relations).

Dengan adanya peran PR yang dilibatkan dalam pengelolaan event, Galeria Mall dapat menyebarkan informasi yang dimiliki tentang event kepada publik melalui semua peran yang dijalankan oleh PR. Di tahun-tahun yang akan datang tentunya peran PR juga pasti akan berkembang sesuai dengan perkembangan teknologi dan PR Galeria Mall mampu untuk terus menjalankan perannya lebih baik lagi.

Sedangkan event-event Plaza Ambarrukmo, dapat semakin diketahui oleh publik dengan kekuatan dari segi publikasi yang dilakukan oleh PR. Peran PR Plaza Ambarrukmo antara lain fasilitator komunikasi (writing media release), fasilitator proses pemecahan masalah (support) dan teknisi komunikasi (publisitas dan media relations).

Peran-peran tersebut sangatlah berpengaruh pada building image dan menaikkan traffic pengunjung. Adapun beberapa gangguan teknis pada saat event berlangsung dapat segera diatasi. Sedangkan peran PR Plaza Ambarrukmo yang lebih banyak pada aktivitas publisitas, dapat memanfaatkan semua media yang ada untuk menyebarkan informasi kepada publik seluas-luasnya mengenai event serta mendapatkan respon positif dari semua kalangan.

\section{Daftar Pustaka}

Iriantara, Yosal. 2005. Media Relations: Konsep, Pendekatan, dan Praktik. Bandung: Simbiosa Rekatama Media.

Morissan. 2008. Manajemen Public Relations: Strategi Menjadi Humas Profesional. Jakarta: Kencana Prenada Media Group.

Noor, Any. 2009. Manajemen Event. Bandung: Alfabeta.

Nova, Firsan. 2009. Crisis Public Relations: Bagaimana $P R$ Menangani Krisis Perusahaan. Jakarta: PT Grasindo.

O’ Toole, William dan Phyllis Mikolaitis. 2007. Corporate Event Management. Jakarta: PPM. 